Pesq. Vet. Bras. 37(2):145-149, fevereiro 2017 DOI: 10.1590/S0100-736X2017000200008

\title{
Aspectos anatomopatológicos em cães naturalmente infectados por Hepatozoon canis $^{1}$
}

\author{
Pâmela A. Lima², Joziana M.P. Barçante ${ }^{3}$, Jankerle N. Boeloni ${ }^{4}$, Pedro S. Bezerra \\ Júnior ${ }^{5}$, Flademir Wouters ${ }^{2}$, Angélica T. Wouters ${ }^{2}$, Mary S. Varaschin ${ }^{2}$ \\ e Josilene N. Seixas ${ }^{3 *}$
}

\begin{abstract}
Lima P.A., Barçante J.M.P., Boeloni J.N., Bezerra Júnior P.S., Wouters F., Wouters A.T., Varaschin M.S. \& Seixas J.N. 2017. [Anatomopathological findings in dogs naturally infected by Hepatozoon canis.] Aspectos anatomopatológicos em cães naturalmente infectados por Hepatozoon canis. Pesquisa Veterinária Brasileira 37(2):145-149. Departamento de Ciências da Saúde, Universidade Federal de Lavras, Campus Universitário, Centro, Lavras, MG 37200-000, Brazil. E-mail: josiseixas@dsa.ufla.br

Canine hepatozoonosis is mainly caused by protozoa Hepatozoon canis and H. americanum that are transmitted by ingestion of infected ticks. Clinical signs may be unspecific or difficult to identify, because usually hepatozoonosis occurs associated with other disease. In Brazil, the parasite and the disease, have been identified in several states, however little is known about the clinical and anatomopathological lesions resulting from the infection. This paper reports five cases of natural infection by Hepatozoon canis in dogs from Minas Gerais State and describes for the first time in Brazil the necropsy and histopathological findings related to infection. Meronts of Hepatozoon sp., submitted to morphometric evaluation, were observed in histological sections of liver, spleen, bone marrow and kidney.
\end{abstract}

INDEX TERMS: Hepatozoon canis, protozoa, canine disease, necropsy, histopathology.

RESUMO.- A hepatozoonose canina é causada principalmente pelos protozoários Hepatozoon canis e H. americanum, transmitida por ingestão de carrapatos parasitados. Os sinais clínicos podem ser inespecíficos ou de difícil reconhecimento, pois geralmente ocorre associada a outras doenças. No Brasil, o parasito, e a doença, já foram identificados em vários Estados, no entanto pouco se sabe sobre as alterações clínicas e anátomo-patológicas decorrentes da infecção. 0 presente trabalho relata cinco casos de infecções naturais por Hepatozoon canis em cães do Es-

\footnotetext{
${ }^{1}$ Recebido em 21 de outubro de 2015.

Aceito para publicação em 15 de julho de 2016.

${ }^{2}$ Departamento de Medicina Veterinária, Universidade Federal de Lavras (UFLA), Campus Universitário, Cx. Postal 3037, Centro, Lavras, MG, 37200-000, Brasil.

${ }^{3}$ Departamento de Ciências da Saúde, UFLA, Campus Universitário, Cx. Postal 3037, Centro, Lavras, MG 37200-000,, Brasil. *Autor para correspondência: josiseixas@dmv.ufla.br

${ }^{4}$ Departamento de Medicina Veterinária, Centro de Ciências Agrárias, Universidade Federal do Espírito Santo (UFES), Alto Universitário s/n, Centro, Alegre, ES 29500-000, Brasil.

${ }^{5}$ Laboratório de Patologia Animal, Faculdade de Medicina Veterinária, Universidade Federal do Pará (UFPA), Campus Castanhal II, Castanhal, PA 68745-000, Brasil
}

tado de Minas Gerais e descreve pela primeira vez no Brasil os achados de necropsias e histopatológicos relacionados à infecção. Merontes de Hepatozoon sp., submetidos a avaliação morfométrica, foram observados em cortes histológicos de fígado, baço, medula óssea e rim.

TERMOS DE INDEXAÇÃO: Hepatozoon canis, protozoários, doenças de caninos, necropsia, histopatologia.

\section{INTRODUÇÃO}

A hepatozoonose canina, doença transmitida por carrapatos, é causada por protozoários do gênero Hepatozoon (Apicomplexa, Hepatozoidae) que parasitam neutrófilos e monócitos dos hospedeiros intermediários (Baneth et al. 2003). No ciclo biológico de Hepatozoon sp. os hospedeiros definitivos são os carrapatos Rhipicephalus sanguineus e Amblyomma spp., nos quais ocorre a esporogonia (Baneth 2011). Os cães e outros mamíferos são considerados hospedeiros intermediários e se infectam pela ingestão destes carrapatos contendo oocistos (Baneth et al. 2003).

Atualmente, duas espécies infectantes de Hepatozoon são responsáveis por alterações clínicas e patológicas distintas em cães (Vincent-Johnson et al. 1997, Baneth et al. 2003): Hepatozoon canis que atinge principalmente órgãos 
hemolinfoides e H. americanum, o sistema músculo esquelético (Baneth 2011).

0 parasito possui distribuição mundial, com maior prevalência da infecção por $H$. canis na África, na Ásia, no Sul da Europa e na América do Norte e do Sul, e por H. americanum nos Estados Unidos (Baneth 2011). No Brasil, há diversos estudos sobre a prevalência do parasito (O'Dwyer et al. 2006, Mundim et al. 2008b, Spolidorio et al. 2009, Gomes et al. 2010), que em algumas regiões foi considerado endêmico (Paludo et al. 2003) e relatos sobre as manifestações clínicas e hematológicas em animais parasitados (Gondim et al. 1998, Paludo et al. 2003, Melo Júnior et al. 2008, Mundim et al. 2008a, Gomes et al. 2010, Silva et al. 2011). No entanto, são escassas as descrições patológicas, com apenas um estudo sobre as alterações histopatológicas em músculos esqueléticos obtidos através de biópsia de três cães parasitados por Hepatozoon sp. (Paludo et al. 2005).

Os sinais clínicos observados na hepatozoonose são inespecíficos e variáveis em intensidade (Vincent-Johnson et al. 1997, Gondim et al. 1998, Baneth et al. 2003, Paludo et al. 2005, Mundim et al. 2008b, O'Dwyer 2011). Em uma revisão feita por Ivanov \& Tsachev (2008) os sinais mais frequentemente relatados em estudos experimentais e infecções naturais foram anemia, edemas e febre intermitente. No Brasil, tem sido identificada infecção com doença subclínica ou branda, frequentemente associada à parasitemia baixa (inferior a 1\% de neutrófilos infectados). No entanto, um quadro clínico mais grave pode ocorrer em filhotes, em animais imunossuprimidos ou quando há infecção concomitante com outros agentes parasitários ou infecciosos, como Toxoplasma gondii, Ehrlichia canis, Babesia canis, Mycoplasma haemocanis, Parvovirus, entre outros (O’Dwyer 2011). A associação com outras hemoparasitoses pode ser atribuída à infestação por carrapatos, que também são transmissores de outros agentes como Ehrlichia sp. e Babesia sp. (Gondim et al. 1998, Baneth et al. 2003, O'Dwyer 2011). Em uma avaliação dos aspectos clínicos e hematológicos de 115 cães naturalmente infectados por Hepatozoon sp. no estado de Minas Gerais, Mundim et al. (2008a) observaram a ocorrência de infecções concomitantes em $22,61 \%$ dos cães, sendo Ehrlichia sp. o agente mais comumente encontrado em associação com Hepatozoon sp.

0 presente artigo tem por objetivo descrever, pela primeira vez no Brasil, os achados de necropsias e histopatológicos relacionados à infecção natural em cinco cães com hepatozoonose.

\section{MATERIAL E MÉTODOS}

Foram encaminhados para necropsia, no Setor de Patologia Veterinária, do Departamento de Medicina Veterinária da Universidade Federal de Lavras (UFLA, Lavras, MG) cinco cães; três fêmeas, sendo uma da raça Australian Cattle Dog, de aproximadamente um ano de idade (canino 1) e as outras duas sem raça definida (SRD), com três (canino 2) e cinco meses de idade (canino 5); e dois machos, um SRD adulto (canino 3) e um Dog Alemão com 3 anos (canino 4). Os fragmentos teciduais coletados foram fixados em formol a $10 \%$ tamponado, processados pelos métodos de rotina de inclusão em parafina, cortados a $5 \mu \mathrm{m}$ e corados com hema- toxilina e eosina para análise histopatológica. Foi realizada análise morfométrica das estruturas parasitárias encontradas nos cortes histológicos.

\section{RESULTADOS}

Os cães eram provenientes do município de Lavras/MG. 0 animal 1 havia sido recentemente adotado de uma propriedade rural. Este apresentava emagrecimento moderado, anemia, hiporexia, dificuldade respiratória, hipotricose multifocal nas regiões torácica e abdominal, infestação acentuada por carrapatos e tumores ulcerados na região medial da tíbia do membro pélvico direito e na região inguinal direita, próximo ao prepúcio - o maior apresentava cerca de 10 $\mathrm{cm}$ de diâmetro. 0 prognóstico reservado e o estado geral do animal levaram o proprietário a optar pela eutanásia. 0 animal 4 vivia em uma propriedade rural e tinha histórico de apatia e dispneia, que culminou com parada cardio-respiratória. 0 animal 2 era mantido em um abrigo para cães abandonados (e foi encontrado morto); os animais 3 e o 5 eram mantidos domiciliados, e não tinham sinais clínicos evidentes (o animal 5 morreu por atropelamento).

Os achados de necropsia (Fig.1, 2 e 3) em quatro cães foram caracterizados principalmente por linfonodos, fíga-

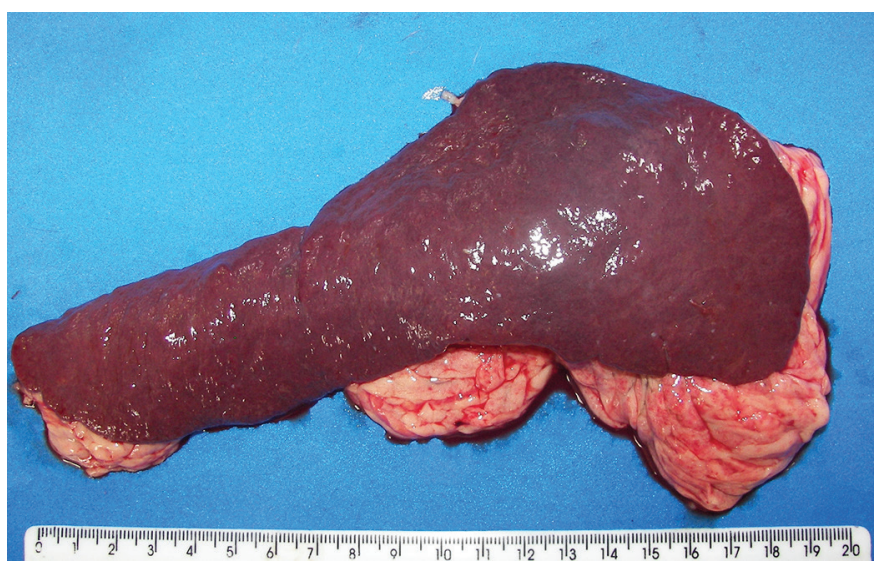

Fig.1. Baço de um cão naturalmente infectado por Hepatozoon canis com aumento de volume acentuado (Canino 1).

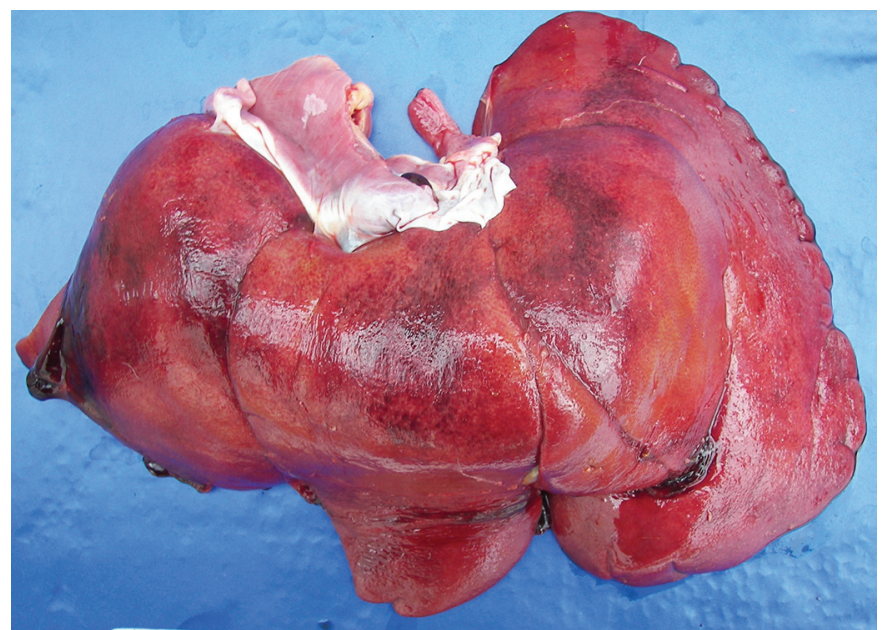

Fig.2. Fígado de um cão naturalmente infectado por Hepatozoon canis com hepatomegalia e fibrina na superfície (Canino 1). 


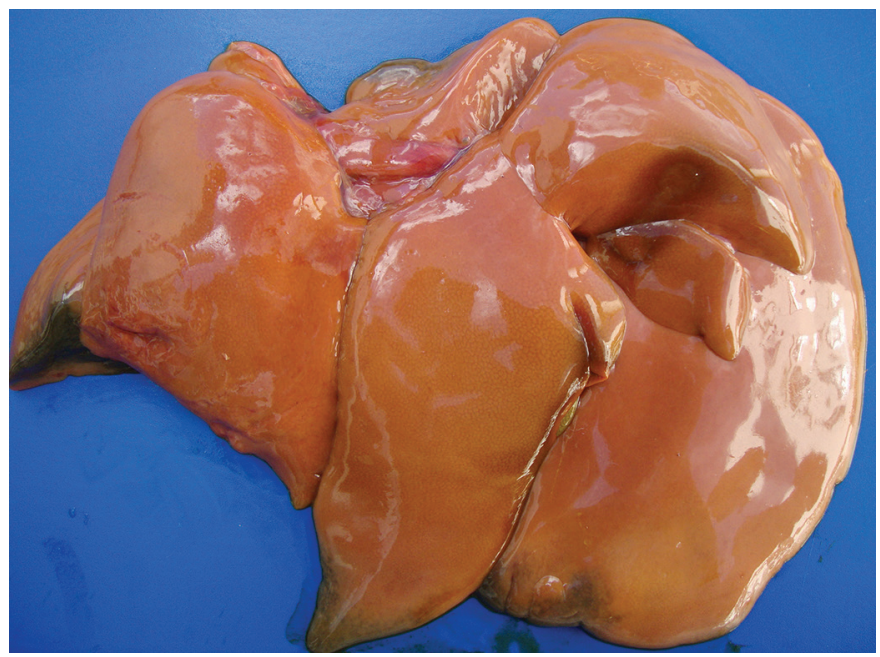

Fig.3. Fígado de um cão naturalmente infectado por Hepatozoon canis amarelado e aumentado de volume (Canino 2).

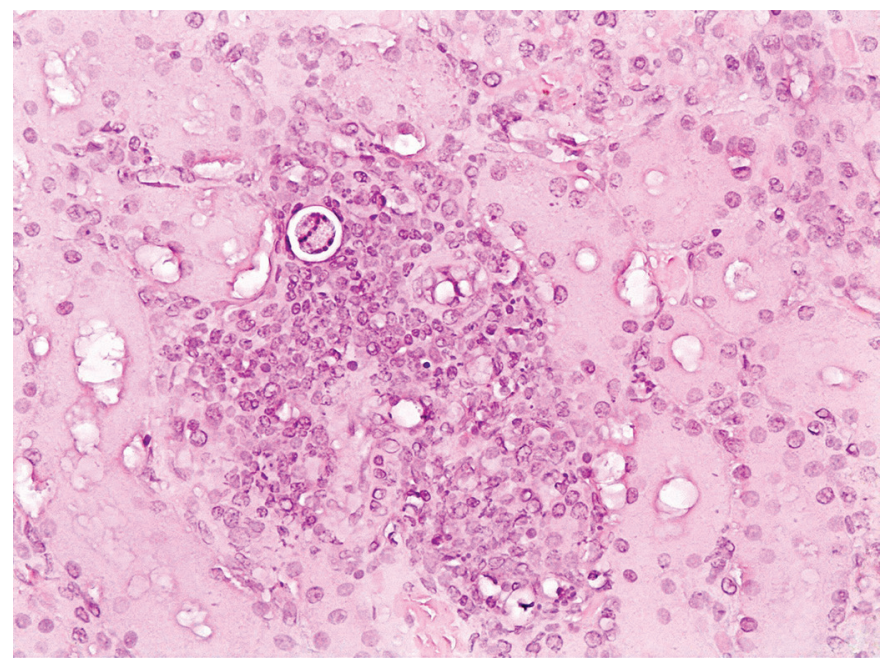

Fig.4. Nefrite linfoplasmocitária associada à meronte de Hepatozoon sp. (Canino 1). HE, obj.20x.

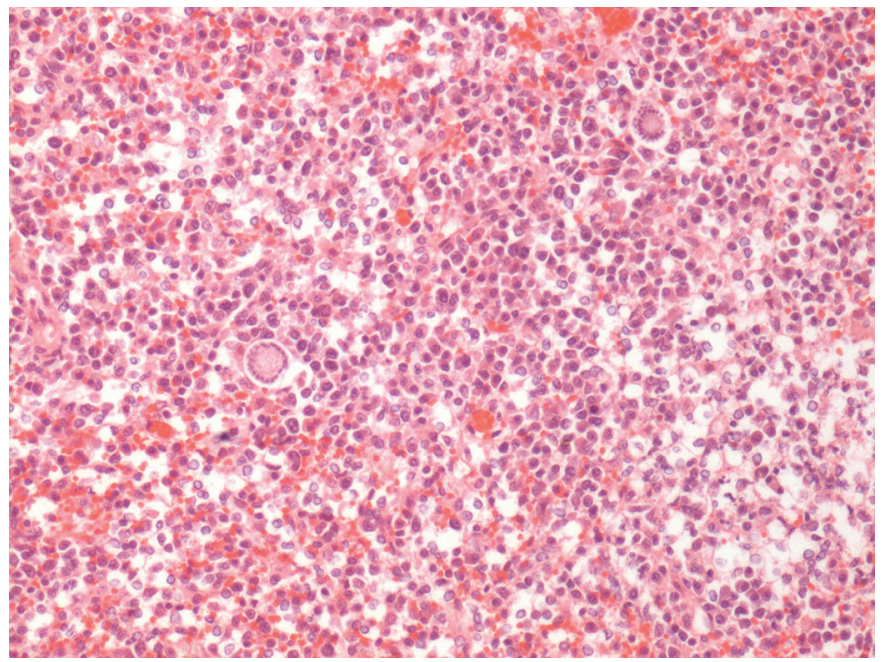

Fig.5. M<merontes de Hepatozoon sp. No baço (Canino 4). HE, obj.10x. do e baço moderadamente aumentados de volume (sendo que o canino 1 apresentava esplenomegalia acentuada); o canino 5, devido ao atropelamento e perda de grande volume de sangue, tinha baço e fígado diminuídos. Em quatro cães, notou-se mucosas conjuntivais e oral moderadamente pálidas e em todos animais edema pulmonar difuso moderado. Os demais achados de necropsia são apresentados no Quadro 1.

Através do exame histopatológico pode-se concluir o diagnóstico destes casos; observaram-se estruturas arredondadas com pontos basofílicos periféricos circundadas por halo não corado, compatíveis com merontes de Hepatozoon sp. no baço dos caninos 1 (pequena quantidade), 2 (grande quantidade), 3 e 4 (raros), no fígado dos caninos 1e 2 (raros), no rim do canino 1 (raros) e na medula óssea dos caninos 1e 2 (pequena quantidade) (Fig.4-5). As demais alterações histopatológicas estão descritas no Quadro 1. Na análise morfométrica das estruturas encontradas nos cortes histológicos de baço, rim fígado e medula óssea foram identificados merontes com aproximadamente $11 \mu \mathrm{m}$ de diâmetro contendo, em média 30 micromerozoítos cada (Fig.6), morfologicamente compatíveis com Hepatozoon canis.

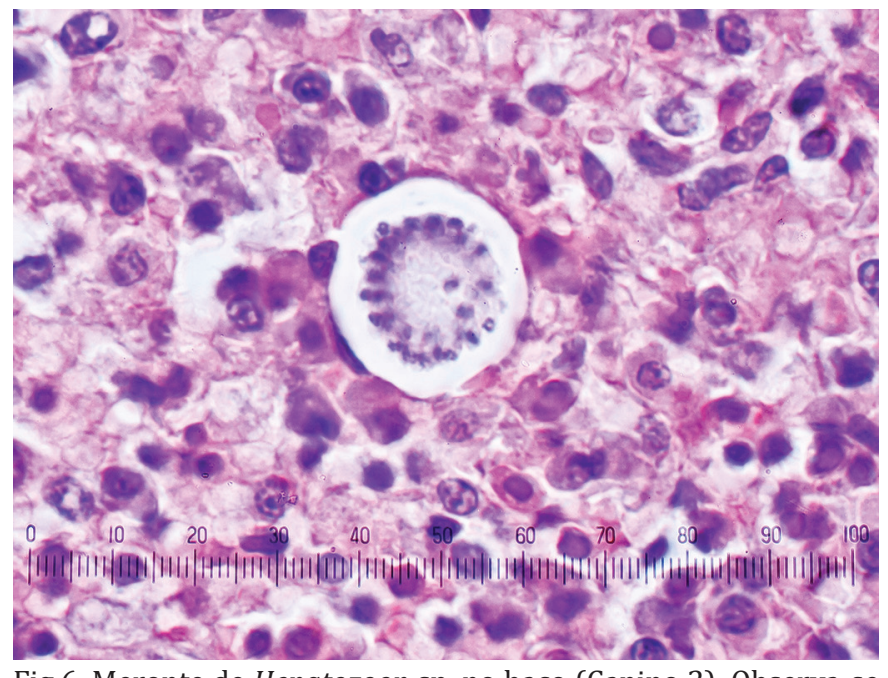

Fig.6. Meronte de Hepatozoon sp. no baço (Canino 2). Observa-se um meronte com medida aproximada de $24 \mu \mathrm{m}$ de diâmetro contendo numerosos micromerozoítos alongados e com núcleos basofílicos e contornados por um halo não corado. HE, obj.40x.

\section{DISCUSSÃO}

Há poucos relatos na literatura sobre as lesões macroscópicas associadas à hepatozoonose causada por Hepatozoon canis. Embora lesões macroscópicas possam não ser observadas (O’Dwyer et al. 2004), anemia, hepato, espleno e linfadenomegalia, também vistos nos cães deste estudo, são lesões que foram associadas à doença (Ivanov \& Tsachev 2008). Além destes achados, estes autores descrevem a caquexia como principal lesão macroscópica, além de atrofia muscular, icterícia discreta, congestão em pulmões e mucosas gástricas e rins pálidos.

Nos cortes histológicos destes casos, as formas teciduais puderam ser facilmente identificadas na coloração 
Quadro 1. Achados adicionais de necropsia e histopatologia de cinco cães com hepatozoonose

Caso Achados de necropsia Achados histopatológicos

Canino 1 Equimoses gengivais. Hipotricose multifocal em regiões torácica e abdominal. Fígado amarelado com coágulos na superfície entre lobos e evidenciação do padrão lobular. Petéquias e equimoses no endocárdio e endocardiose moderada. Rins com superfície discretamente irregular. Área hemorrágica na base do crânio.

Canino 2 Equimoses em pavilhão auricular, região ventral do abdômen e região proximal do MTE. Edema subcutâneo. Hidrotórax. Pulmões com extensas áreas firmes, amareladas e exsudato purulento. Fígado intensamente amarelado. Intestino grosso e delgado com moderada quantidade de Toxocara canis (20 exemplares).

Canino 3 Pele com quantidade moderada de carrapatos, ulcerações em MPD e massa de $8 \mathrm{~cm}$ de diâmetro na região inguinal lateral direita; edema em subcutâneo da região inguinal lateral esquerda. Linfonodos inguinais com moderado aumento de volume, ao corte áreas brancacentas e avermelhadas e perda de limite entre região cortical e medular Pulmões com áreas firmes e enfisema. Endocardiose em valva mitral. Baço com discreta evidenciação de polpa branca e placas siderofibróticas. Rins moderadamente avermelhados.

Canino 4 Cavidade abdominal com moderada quantidade de líquido seroso avermelhado. Baço com áreas de fibrose e polpa branca evidente ao corte. Fígado mais friável, com evidenciação do padrão lobular e fibrina em quantidade moderada em sua superfície. Mucosa do estômago com pregas espessadas e irregulares nas regiões fúndica e pilórica. Intestino com abundante quantidade de parasitos compatíveis com Toxocara canis e Dipilydium. Linfonodos mesentéricos e poplíteos: aumentados de volume. Coração dilatado em ambas as câmaras, com músculo papilar achatado, especialmente em lado esquerdo. Rins com pontilhados esbranquiçados multifocais na superfície externa.

Canino 5 Moderada quantidade de sangue nas cavidades abdominal e torácica. Intestino, com áreas de depressão das placas de Peyer e conteúdo sanguinolento. Baço pálido. Fígado difusamente pálido, com acentuação do padrão lobular. Rins pálidos, com coágulo subcapsular e demarcação linear avermelhada estendendo difusamente entre cortical e medular. Coração com pontos brancacentos milimétricos difusamente no endocárdio; sobre a válvula mitral, coloração esbranquiçada (lesão por jato) e tricúspide levemente edemaciada. Pulmões difusamente avermelhados, pesados e com diminuição da crepitação. Pâncreas, fígado, bexiga, timo, intestino e diafragma com hemorragias multifocais.

TEM = membro torácico esquerdo; MTD = membro torácico direito.
Linfonodo com hiperplasia de folículos secundários, macrófagos com hemossiderina em seios medulares; discreto infiltrado inflamatório mononuclear multifocal no miocárdio; pulmões com espessamento de septos interalveolares por discreto infiltrado inflamatório mononuclear multifocal; fígado com infiltrado mononuclear periportal discreto, congestão moderada, hemossiderose difusa discreta, hemorragias focais e raras células em cariorrexe na região centrolobular; baço com hemossiderose difusa moderada, poucos megacariócitos; nefrite intersticial discreta; e hemorragias multifocais discretas entre as camadas granulosa e molecular do cerebelo.

Broncopneumonia fibrino-purulenta multifocal a coalescente acentuada; e hemossiderose hepática discreta. Os demais órgãos apresentavam autólise acentuada.

Pele com proliferação neoplásica sólida e infiltrativa, necrose e hemorragias multifocais moderadas, ulceração extensa, associada a infiltrado inflamatório misto; metástase com áreas centrais extensas de necrose em linfonodo; congestão hepática difusa moderada e infiltrado inflamatório mononuclear discreto em região portal; baço com congestão difusa e hemorragia multifocal moderada, hemossiderose difusa discreta e pequena quantidade de megacariócitos; nefrite intersticial linfoplasmocítica multifocal discreta e substância amorfa e hialina em glomérulos.

Pulmões com pneumonia intersticial difusa com infiltrado de neutrófilos e macrófagos espumosos intra-alveolares (raros contendo hemossiderina); hipertrofia acentuada de musculatura lisa de bronquíolos terminais e parede de artérias. Coração com hipertrofia de cardiomiócitos. Rins com espessamento de cápsula de Bowman, glomerulonefrite membranosa, nefrite intersticial multifocal moderada e congestão difusa acentuada. Fígado com atrofia de cordões de hepatócitos, congestão centrolobular e perilobular com fibrose centrolobular. Próstata com infiltrado linfoplasmocitário focalmente extenso. Intestino delgado com discreta dilatação de criptas (com conteúdo necrótico) e folículos linfoides hiperplásicos. Linfonodo com edema e proliferação plasmocítica difusa moderada. Estômago com hipertrofia e hiperplasia acentuadas da mucosa.

Rim com infiltrado linfoplasmocitário discreto e multifocal, glomérulos com cápsula de Bowman espessada, pequena quantidade de proteína intratubular e fibrose difusa moderada na medular, com áreas de hemorragia e necrose tubular. Medula óssea hipoplásica. Pulmão com congestão difusa acentuada. Intestino grosso - mucosa com hemorragia difusa acentuada com trombos na submucosa. Linfonodo hiperêmico. por HE, e como relatado por outros autores (Baneth \& Weigler 1997) os parasitos foram detectados principalmente em baço, fígado e medula óssea; que também os descreveram em linfonodos, pulmões, rins e pleura. Normalmente não há reação tecidual associada, no entanto, no momento em que os merozoítos são liberados, uma resposta inflamatória intensa pode ser detectada, com maior quantidade de macrófagos e neutrófilos e número variável de eosinófilos (Ivanov \& Tsachev 2008). Apenas em um foco observou-se nefrite linfoplasmocítica associada ao meronte de Hepatozoon sp (canino 1), no entanto em quatro cães lesões renais, especialmente nefrite intersticial foi um achado comum. Os cães com alta parasitemia podem apresentar hepatite, pneumonia e glomerulonefrite associadas à merontes de $H$. canis (Baneth \& Weigler 1997).
Além do diagnóstico histopatológico, descrito pela primeira vez no Brasil pelo presente trabalho, a hepatozoonose canina também pode ser diagnosticada através de testes sorológicos, como imunofluorescência indireta, ELISA (O’Dwyer 2011); e pela técnica de reação em cadeia da polimerase (PCR) (Otranto et al. 2011) ou mesmo pela identificação de gamontes em preparações citológicas de esfregaços sanguíneos ou aspirados de tecidos hemolinfáticos (Baneth et al. 2003). No presente relato esses exames não foram realizados, pois não havia suspeita clínica da doença. Além disso, os antígenos utilizados para esses testes são obtidos de cães com alta parasitemia, característica incomum no Brasil (Baneth et al. 2003, O’Dwyer 2011).

0 fato de o parasito poder ser detectado em leucócitos de cães clinicamente normais leva a acreditar que condi- 
ções de imunossupressão possam estar envolvidas na patogênese da doença (Vincent-Johnson et al. 1997, Gondim et al. 1998, Baneth et al. 2003). Nos animais deste estudo foram identificados como possíveis fatores predisponentes: baixo escore corporal, hipoproteinemia (anemia e edemas), pneumonia, cardiopatia, helmintoses e/ou a neoplasia maligna metastática.

Há escassos relatos sobre a parasitemia no Estado de Minas Gerais (Mundim et al. 2008a), no entanto, no estudo realizado por Gomes et al. (2010) foi verificada em Uberlândia, uma prevalência de $7,66 \%$ de cães parasitados. Embora ocorra na maioria das vezes como doença subclínica, a hepatozoonose deve ser considerada no diagnóstico diferencial, principalmente em casos de suspeita de hemoparasitoses. Assim, é preciso estar alerta para a ocorrência da hepatozoonose na região sul de Minas Gerais, uma vez que esta apresenta similaridade com outras doenças infecciosas ou pode ocorrer concomitantemente como agravante do quadro clínico destes animais.

A associação dos achados macroscópicos com a visualização de merontes compatíveis com $H$. canis ao exame histopatológico, associada à descrição morfológica do parasito permitiu a confirmação do diagnóstico.

Agradecimentos.- À Fundação de Amparo à Pesquisa do Estado de Minas Gerais-FAPEMIG, pela colaboração nesse trabalho.

\section{REFERÊNCIAS}

Baneth G. 2011.Perspectives on canine and feline hepatozoonosis. Vet. Parasitol. 181:3-11.

Baneth G. \& Weigler B. 1997. Retrospective case-control study of hepatozoonosis in dogs in Israel. J. Vet. Intern. Med. 11(6):365-370.

Baneth G., Mathew J.S., Shkap V., Macintire D.K., Barta J.R. \& Ewing S.A. 2003. Canine hepatozoonosis: two disease syndromes caused by separate Hepatozoon spp. Trends Parasitol. 19(1):27-31.

Gomes P.V., Mundim M.J.S., Mundim A.V., Ávila D.F., Guimarães E.C. \& Cury M.C. 2010. Occurrence of Hepatozoon sp. in dogs in the urban area originating from a municipality in southeastern Brazil. Vet. Parasitol. 174(1/2):155-161.

Gondim L.F.P., Kohayagawa A., Alencar N.X., Biondo A.W., Takahira R.K. \&
Franco S.R.V. 1998. Canine hepatozoonosis in Brazil: description of eight naturally occurring cases. Vet. Parasitol. 74:319-323.

Ivanov A. \& Tsachev I. 2008. Hepatozoon canis and hepatozoonosis in the dog. Trakia J. Sci. 6 (2):27-35.

Melo Júnior O.A., Miranda F.J.B., Almeida J., Albernaz A.P. \& Machado J.A. 2008. Hepatozoonose canina em Campos dos Goytacazes, RJ. Arq. Ciênc. Vet. Zool. Unipar 11(1):73-75.

Mundim A.V., Moraes I.A., Taveres M., Cury M.C. \& Mundim M.J.S. 2008a. Clinical and hematological signs associated with dogs naturally infected by Hepatozoon sp. and with other hematozoa: a retrospective study in Uberlândia, Minas Gerais, Brazil. Vet. Parasitol. 153:3-8.

Mundim E.C.S., Francisco M.M.S., Souza J.N., Alencar M.A.G. \& Ramalho P.C.D. 2008b. Incidência de hemoparasitoses em cães (Canis familiaris) de rua capturados pelo Centro de Controle de Zoonoses (CCZ) da cidade de Anápolis-GO. Ens. Ciênc., Ciênc. Biol. Agr. Saúde 12(2):107-115.

O’Dwyer L.H. 2011. Brazilian canine hepatozoonosis. Revta Bras. Parasitol. Vet. 20(3):181-193.

O’Dwyer L.H., Saito M.E., Hasegawa M.Y. \& Kohayagawa A. 2004. Tissue stages of Hepatozoon canis in naturally infected dogs from São Paulo State, Brazil. Parasitol. Res. 94:240-242.

O’Dwyer L.H., Saito M.E., Hasegawa M.Y. \& Kohayagawa V. 2006. Prevalence, hematology and serum biochemistry in stray dogs naturally infected by Hepatozoon canis in São Paulo. Arq. Brasil. Med. Vet. Zootec. 58(4):688-690.

Otranto D., Torres F.D., Weigl S., Latrofa M.S., Stanneck D., Decaprariis D., Capelli G. \& Baneth G. 2011. Diagnosis of Hepatozoon canis in young dogs by cytology and PCR. Parasit. Vectors 4:55-60.

Paludo G.R., Dell'Porto A., Trindade A.R.C., McManus C. \& Friedman H. 2003. Hepatozoon spp.: report of some cases in dogs in Brasília, Brazil. Vet. Parasitol. 118:243-48.

Paludo G.R., Friedmann H., Dell'Porto A., Macintire D.K., Whitley E.M., Boudreaux M.K., Baneth G., Blagburn B.L. \& Dykstra C.C. 2005. Hepatozoon spp.: pathological and partial 18S rRNA sequence analysis from three Brazilian dogs. Parasitol. Res. 97:167-170.

Silva A.S., França R.T., Soares J.F., Girotto A., Monteiro S.G., Labruna M.B. \& Lopes S.T.A. 2011. Report of a clinical case of dog infected by Hepatozoon canis in Southern Brazil. Comp. Clin Pathol. 20:669-672.

Spolidorio M.G., Labruna M.B., Zago A.M., Donatele D.M., Caliari K.M. \& Yoshinari N.H. 2009. Hepatozoon canis infecting dogs in the State of Espírito Santo, southeastern Brazil. Vet. Parasitol. 163:357-361.

Vincent-Johnson N.A., MacIntire D.K., Lindsay D.S., Lenz S.D., Baneth G., Shkap V. \& Blagburn B.L. 1997. A new Hepatozoon species from dogs: description of the causative agent of canine hepatozoonosis in North America. J. Parasitol. 83:1165-1172. 